YAK 338.2

В.А. Анареев ${ }^{1}$

Владивостокский государственный университет экономики и сервиса

Владивосток. Россия

Сайнявонг Ампхаван ${ }^{2}$

Управление экономики и развития преАпринимательства г. Владивостока

Владивосток. Россия

\title{
Социально-экономическое развитие
}

Ааосской Народно-Аемократической Республики

на современном этапе:

\section{специфика, противоречия и перспективы}

Цель исслеАования - изучение процессов социально-экономического развития Ааосской НародноАемократической Республики на современном этапе и выявление перспективных направлений развития страны до 2020 года. ПреАмет исслеАования - существующие противоречия и особенности социальноэкономического развития, обусловленные страновой спецификой Ааоса. МетоА исслеАования - анализ основных результатов реализации документов стратегического планирования, разработанных и реамизуемых в рамках курса "Новой экономической модели". Анализ показывает, преимущественно, что экономика Ааоса связана с Аобычей природных ресурсов, гАе ограничена занятость местного населения. Аоминирует сельское хозяйство, гАе большая часть населения продолжает заниматься низкоквалифицированным трудом. Отток капитала и слабое государственное финансовое управление препятствуют росту Аохолов от использования природных ресурсов. Следовательно, сокращение масштабов нищеты иАет меАленнее по сравнению со соседними странами, несмотря на высокие темпы роста экономики. Определено, что перспективные направления социально-экономического развития Ааосской НародноАемократической Республики формируются за счет устойчивых каналов пространственного развития в приграничных участках р. Меконг с учетом трансграничных направлений сырьевых, товарных и транспортных потоков. Развитие ^аоса предусматривает размещение точек роста - особых экономических зон на территориях с выгодным Аоступом к перспективным рынкам, что способствует переносу производства рыночных товаров и услуг ближе к рынкам потребления, на приграничные территории с Королевством ТаиланА, Вьетнамом и Камбоджей. Практическая значимость работы закмючается в рассмотрении положений, раскрывающих содержание планирования социально-экономического развития Ааоса, позволяющих углубить преАставления о сущности и соАержании, принципах и инструментах реализации политики страны в Аанной сфере.

Ключевые слова и словосочетания: Ааос, страны Большого Меконга, Юго-Восточная Азия, страны ACEAH.

Андреев Вячеслав Андреевич - доцент кафедры управления, e-mail: andreev_va@inbox.ru.

Сайнявонг Ампхаван - практикант Управления экономики и развития предпринимательства г. Владивостока; e-mail: amphavanhxyv@gmail.com 


\author{
V.A. Andreev ${ }^{1}$ \\ Vladivostok State University of Economic and Service \\ Vladivostok. Russia \\ Amphavanh Xayavong² \\ Department of economics and entrepreneurship of Vladivostok \\ Vladivostok. Russia
}

\title{
Ongoing processes, contradictions and prospects of social and economic development in Lao PDR
}

\begin{abstract}
Purpose of studying is the processes of socio-economic development in Lao people's Democratic Republic at present stage and identification of directions of the country's development until 2020. Subject of research is identification of contradictions and features of socio-economic development due to the country's specifics of Laos. Research method is represented by analysis of major results of the implementation of strategic planning documents which implemented in the framework of course the "New economic model". The analysis shows that the economy of Laos is mainly connected with the extraction of natural resources, where the employment of the local population is limited. Agriculture dominates, with the majority of the population still engaged in low-skilled work. Capital outflows and weak public financial management have impeded the growth of revenues from natural resources. Consequently, poverty reduction is slower than in neighboring countries, despite high economic growth. It is determined that the promising directions of socio-economic development in the Lao people's Democratic Republic are formed through sustainable channels of spatial development in the border areas of the Mekong river, taking into account the cross-border directions of raw materials, commodity and transport flows. The development of Laos aims at placement of special economic zones in areas with favorable access to sales markets, which contributes to transfer of production of market goods and services closer to consumer markets, to the border areas with the Kingdom of Thailand, Vietnam and Cambodia. Practical significance of the work is reviewing the findings that reveal content of socio-economic development in Laos, allowing to deepen the understanding of its nature and content, principles and tools of the country's policy in this field.
\end{abstract}

Keywords: Laos, countries of the Big Mekong region, Southeast Asia, ASEAN countries.

\section{Введение}

Социально-экономическое развитие Лаосской Народно-Демократической Республики имеет национальные особенности, обусловленные практикой государственного планирования экономики, географическим расположением страны и ее хозяйственно-экономической специализацией, этнокультурными традициями, наследием недавних войн. Став независимым в 1975 году, Лаос установил контроль над экономикой через централизованное управление, которое длилось вплоть до 1985 года. В течение этого периода Правительство Лаоса сделало вывод, что экономические меры не смогли достичь ожидаемых целей. Успехи были слабыми из-за нехватки квалифицированной рабочей силы, и, хотя страна привлекала внешнюю помощь, многие проекты не были завершены на удовлетворительном

\footnotetext{
${ }^{1}$ Andreev Vyacheslav Andreevich - associate professor of the department of management; e-mail: andreev_va@inbox.ru). 2 Amphavanh Xayavong - intern, Department of economics and entrepreneurship of Vladivostok; e-mail: amphavanhxyv@gmail.com.
} 
В.А. Андреев, С. Ампхаван. Социально-экономическое развитие АНАР на современном этапе...

уровне. В 1986 году была начата экономическая реформа, направленная на переход от централизованной плановой экономики к рыночной, ориентированной на «Новый экономический механизм», цель которого - трансформация социалистической системы управления экономикой в рыночную [5].

Были поставлены две основные политические цели, в том числе политика «открытого рынка» и внедрение рыночных экономических принципов. Лаос провел значительные экономические и институциональные реформы, направленные на улучшение социального и экономического благосостояния населения, последовательно создавая рыночную экономику. Общая стратегия Правительства Лаосской Народно-Демократической Республики на современном этапе заключается в оказании помощи бедным, чтобы помочь в полной мере использовать свой труд и скромные ресурсы, улучшить свое положение и выйти из бедности [6].

Вместе с тем Правительство страны столкнулось с рядом проблем, которые затрагивают многие развивающиеся страны. Экономика страны все еще хрупкая, так как существует большой дефицит бюджета. Внутреннее производство и услуги по-прежнему имеют более высокие издержки по сравнению с соседними странами, в результате чего способность к конкуренции низкая, поскольку большинство производств основано на импорте и использовании инструментов и методов, которые устарели. Нарушение законов и нормативных актов все еще имеет место, особенно характерны незаконные экспортные и импортные операции с такими товарами, как нефтепродукты и транспортные средства, что снижает доходы в бюджет страны. Поддержка и оценка реализации инвестиционных проектов по-прежнему не имеет эффективной системы, влияют отсутствие реальных отчетов о достигнутых результатах, задержки с реализацией проектов или отсутствие результатов их реализации. Существуют и другие социально-экономические проблемы, сдерживающие развитие Лаоса и обусловленные особенностями страны [1].

\section{Цель, предмет и метод исследования}

Цель статьи в исследовании специфики процессов социально-экономического развития Лаосской Народно-Демократической Республики на современном этапе состоит в выявлении проблем и перспективных направлений ее стратегического развития до 2030 года. Предмет исследования в рамках статьи - существующие противоречия и особенности социально-экономического развития Лаоса, перспективные пути устранения структурных диспропорций хозяйственно-экономической системы страны. Метод исследования - анализ основных результатов реализации документов стратегического планирования, разработанных и реализуемых в рамках курса «Новой экономической модели».

В рамках поставленной цели проведен анализ текущей макроэкономической ситуации, реализации мероприятий 7-го пятилетнего плана социально-экономического развития, а также результатов реализации стратегических проектов в сфере экономики в Лаосской Народно-Демократической Республике. Рассматриваются прогноз и перспективы развития страны в рамках реализации 8-го пятилетнего плана социально-экономического развития, приведена оценка реализации стратегических проектов в сфере экономики с международной финансовой поддержкой в 
Лаосской Народно-Демократической Республике. Практическая значимость работы заключается в рассмотрении положений, раскрывающих содержание стратегического планирования социально-экономического развития Лаоса, позволяющих углубить теоретические представления о сущности и содержании, принципах и инструментах реализации политики страны в данной сфере.

\section{Обзор исследований по данной тематике}

Несмотря на положительные результаты реализации объявленной Правительством Лаоса «Новой экономической модели» развития, страна занимает 139 место среди 190 стран в рейтинге Всемирного банка «Ведение бизнеса 2017» ${ }^{1}$ и предпоследнее место среди стран-членов Ассоциации государств Юго-Восточной Азии. Страна имеет низкий рейтинг по условиям процедур и процессов для начала бизнеса, подключения к электричеству, защиты миноритарных акционеров и урегулирования несостоятельности. Отсутствие доступа к финансированию является еще одним фактором, который ограничивает, в частности, малые и средние предприятия в организации предприятий с высокой занятостью.

В стране есть богатые, но более 75 процентов людей зарабатывают менее двух американских долларов в день. Многие из людей, живущих в низинах Лаоса, добиваются большего успеха, но самые бедные все еще живут в горных районах, удаленных от реки Меконг. В целом, Лаос остается одной из самых бедных стран в мире (уровень бедности $23,2^{2}$ процента). Ожидаемая продолжительность жизни здесь составляет лишь около 60 лет для мужчин и 64 года для женщин, хотя в последние годы оба показателя и выросли [4].

Страна привлекла значительные иностранные инвестиции для развития отрасли гидроэнергетики. Особенно важным в реализации данных проектов было начало работы в марте 2010 года гидроэлектростанции «Нам Теун 2». Это самая крупная гидроэлектростанция в Лаосе, экспортирующая электроэнергию в Королевство Таиланд [2]. В то время как строительство плотин принесло увеличение доходов в страну, эти усилия оказались далеко не бесспорными. Вследствие активного роста импорта материалов и оборудования для строительства гидроэлектрических плотин, а также импорта значительной части потребительских товаров в 2015 году торговый дефицит увеличился до 20 процентов от ВВП, а дефицит бюджета, в основном из-за торгового дефицита, достиг значения 17 процентов от ВВП, хотя долгое время в предыдущий период составлял от 2 до 4 процентов от ВВП. Таким образом, важной задачей для Лаоса является сокращение дефицита бюджета до 4-6 процентов от ВВП в краткосрочный период, а в среднесрочной перспективе обеспечение сбалансированности бюджета [10].

Второй по значимости отраслью для инвестиций считается туризм. Согласно последним оценкам в 2017 году эту страну посетило более $3,860^{3}$ миллиона человек, и ожидается, что численность и воздействие на экономику возрастут.

\footnotetext{
Данные Всемирного Банка. URL: http://russian.doingbusiness.org/reports/global-reports/doing-business-2017

2 Данные Азиатского Банка Развития. URL: https://www.adb.org/countries/lao-pdr/poverty

3 Данные Министерства информации, культуры и туризма Лаоса. URL: http://www.tourismlaos.org/files/ files/2017\%20Statistic\%20Report.pdf
} 
В.А. Андреев, С. Ампхаван. Социально-экономическое развитие АНАР на современном этапе...

Кроме того, Лаос обладает преимуществом географического местоположения для коммерческих грузовых перевозок и транзитных услуг в другие страны в рамках региона Большой Меконг (Greater Mekong Sub region), в который входят также Камбоджа, Китай, Мьянма, Королевство Таиланд и Вьетнам. Для использования преимущества членства в данной организации были усовершенствованы правовые инструменты и созданы некоторые новые, которые создадут благоприятные факторы для содействия социально-экономическому развитию Лаоса. Членство в ВТО и АЭС расширит возможности для привлечения большего количества инвестиций, торговли и услуг в Лаосскую НДР, а также изучения опыта и уроков в сфере социально-экономического развития страны в средне- и долгосрочный период [7].

В долгосрочный период до 2030 года в рамках курса «Новая экономическая модель» Лаос продолжит выполнение экономических программ, направленных на реализацию имеющегося потенциала с учетом национальных особенностей. Для Лаоса важными направлениями стратегического планирования остается устойчивое развитие сельскохозяйственных территорий, поддержка сельских общин, решение вопросов здравоохранения и образования. Среди наиболее приоритетных направлений - превращение страны в коммуникационный центр Юго-Восточной Азии, а также в своего рода «энергетический центр АСЕАН», для чего Лаос предполагает войти в число ведущих экспортеров электроэнергии в регионе реки Меконг и Юго-Восточной Азии [2].

\section{Основная часть}

В рамках курса «Новая экономическая модель» планами стратегического развития предусмотрено к 2020 году полностью вывести Лаос из числа беднейших стран мира, устранить диспропорции в экономическом развитии 3 основных регионов Лаоса (северный, центральный, южный), решить проблемы отсутствия современной промышленности, транспортной и инженерной инфраструктуры, нехватки квалифицированных кадров.

Особенностью Лаоса является система управления экономикой в рамках реализации пятилетних планов социально-экономического развития, которые содержат важнейшие цели развития страны и соответствующие меры по их достижению. Планы служат общей основой для мобилизации и координации ресурсов как национальных, так и международных партнеров для достижения целей развития страны. В марте 2011 года Национальным собранием был принят 7-й план социальноэкономического развития на 2011-2015 гг., и он уделял гораздо более пристальное внимание всестороннему росту и достижению целевых показателей по дальнейшему развитию страны к окончанию действия национальной стратегии к 2020 году.

В период реализации 7-летнего плана социально-экономического развития общие инвестиции в проекты в Лаосе (включая государственный бюджет, гранты и займы, внутренние и иностранные частные инвестиции, инвестиции в банковскую систему) составили 248761,28 млрд кипов ${ }^{4}$, что практически в 2 раза превысило целевой показатель пятилетнего плана (127 трлн кипов). Инвестиции увеличились с 28 663,23 в 2011 году до 44 359,03 млрд кипов в 2015 году, что соответствовало 43,3

${ }^{4}$ Кип - денежная единица Лаоса, 1 доллар США равняется 8431,88 лаосским кипам на 29.07.2018 г. 
процента от ВВП. Рост инвестиций свидетельствовал об интересе иностранных партнеров к проектам в Лаосе и налаживании фискальной дисциплины, способствующей мобилизации внутренних финансовых ресурсов [8].

В течение последнего десятилетия реальные темпы роста ВВП в стране колебались в пределах 7-8 процентов. К сожалению, рост был довольно неравномерным, а результаты развития для большинства населения страны неочевидны. В 2016 году валовой продукт впервые с 2005 года снизился на 0,5 процента к предыдущему году до значения 6,9 процента. Согласно данным Международного валютного фонда номинальный ВВП Лаоса в 2016 году составил \$ 13,8 млрд (121 место среди 190 стран). Номинальный ВВП на душу населения составил US\$1,925 (140 место среди 190 стран). Таким образом, Организация Объединенных Наций классифицирует Лаос как слаборазвитую страну, несмотря на устойчивые темпы экономического роста [10].

Особенностью экономического развития Лаосской НДР является использование преимущества расположения в центре субрегиона Большого Меконга (СБМ). Хотя стране не хватает прямого доступа к морю, это единственная страна, граничащая со всеми пятью странами СБМ. Ключевое стратегическое положение позволяет Лаосской Народно-Демократической Республике стать важнейшей страной транзита для торговли в регионе Меконга и между регионом Меконга и регионом Ассоциации государств Юго-Восточной Азии (АСЕАН), Восточной Азии и за ее пределами. Доля торговли с пятью другими странами СБМ в 2005-2015 годах увеличилась с 57,4 до 83,7 процента для экспортных операций и с 83 до 89,9 процентов для импорта [7].

Специфичная черта экономики Лаоса связана с добычей природных ресурсов, где ограничена занятость местного населения, и доминированием сельского хозяйства, где большая часть рабочей силы продолжает заниматься низкоквалифицированным трудом. В результате, несмотря на высокие темпы экономического роста, создается мало рабочих мест, а доходы остаются низкими. В период активного экономического развития с 2003 по 2012 год каждый процентный пункт роста ВВП сопровождался в среднем ростом бедности на 0,47 процента. Отток капитала и слабое государственное финансовое управление препятствуют использованию доходов от добычи природных ресурсов. Таким образом, сокращение масштабов нищеты идет медленнее по сравнению с соседними странами, недоедание продолжает оставаться высоким, риск попасть в нищету реален для значительной части населения [9].

Индикаторы благосостояния еще хуже для этнических меньшинств, гендерный разрыв проявляется в образовании и здравоохранении. Рост бремени государственного долга, системных рисков в финансовом секторе и низких резервных фондов может подорвать макроэкономическую стабильность, что может увеличить инфляцию, снизить уровень жизни и сократить объем предоставления государственных услуг [3].

Продолжающаяся деградация окружающей среды вредит населению и ставит под сомнение перспективы роста, а вместе с изменением климата увеличит и без того высокие риски стихийных бедствий. Если какой-либо из этих рисков матери- 
В.А. Андреев, С. Ампхаван. Социально-экономическое развитие АНАР на современном этапе...

ализуется, бедные, скорее всего, будут наиболее затронуты, поскольку у них есть меньше возможностей для смягчения рисков.

Низкое воздействие экономического роста на бедность в Лаосской НародноДемократической Республике в первую очередь является результатом модели роста, которая в значительной степени зависит от высококапиталоемких секторов, таких как гидроэнергетика и горная промышленность, а не от производства с высокой занятостью населения. Инвестиции в горнодобывающие и гидроэнергетические компании позволяют создавать анклавы роста и процветания с ограниченными связями с остальной экономикой. Даже когда такие анклавные отрасли быстро растут, они создают гораздо меньше рабочих мест, чем новые предприятия, на которых производят такие товары, как одежда, обувь и бытовая электроника. Эта изоляция не снижает уровень бедности, даже когда рост ВВП является сильным [4].

Следует вывод, что, хотя Лаосская Народно-Демократическая Республика была одной из наиболее быстрорастущих экономик Юго-Восточной Азии за последнее десятилетие, уровень сокращения масштабов нищеты не был соизмерим с силой экономического роста. Чтобы сделать этот рост более всеобъемлющим в будущем, необходимо перенести источники роста из добывающих отраслей в производство с высокой добавленной стоимостью и высокой занятостью.

Наличие проблем социально-экономического развития Лаосской НародноДемократической Республики, указывает на необходимость решения ряда принципиально важных задач к 2020 году в рамках реализации 8-го плана социальноэкономического развития, к которым относятся:

- устранение структурной диспропорций сложившейся хозяйственно-экономической и пространственной системы Лаоса за счет экономически обоснованного размещения производительных сил и формирования условий для создания экономических секторов с высокой занятостью населения и высокой добавленной стоимостью;

- использование межрегиональных и трансграничных связей с учетом выгодного экономико-географического положения Лаоса в регионе р. Меконг;

- диверсификация экономической деятельности за счет создания производств с высокой добавленной стоимостью и высокой занятостью, что особенно актуально в сельскохозяйственных регионах Лаоса для снижения уровня бедности и социальной напряжённости.

Перспективными планами социально-экономического развития Лаосской НДР предусматривается обеспечить устойчивые темпы экономического роста: 7,1 процента в 2018 г., 7,02 процента в 2019 г., 6,9 процента в 2020 году5. Предполагается, что в 2020 году ВВП в денежном выражении составит 20,5 млрд. долларов США, или 2059 долларов на душу населения (численность населения прогнозируется 7290000 человек). Уровень безработицы составит 1,7 процента, а дефицит бюджета не превысит 6,1 процента к валовому внутреннему продукту.

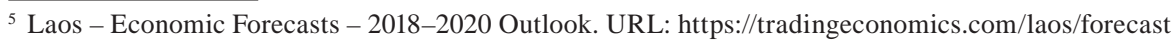


Перспективным направлением социально-экономического развития Лаосской Народно-Демократической Республики станет формирование и дальнейшее развитие особых экономических зон в приграничных участках р. Меконг с учетом направлений трансграничных сырьевых, товарных и транспортных потоков. Предполагается, что транспортные потоки в регионе Большой Меконг трансформируются в экономические коридоры посредством содействия торговле и транспорту, развития городов-коридоров, поддержки туризма и инвестиций и продвижения совместных предприятий. Это будет способствовать расширению малых и средних предприятий и сельского хозяйства, включая интеграцию в региональные сети поставок и производственные сети, что обеспечит диверсификацию экономики [9].

Помимо развития инфраструктуры, например, дорог и энергетики, программа сотрудничества в регионе Большой Меконг способствует региональной безопасности в области здравоохранения, включая профилактику инфекционных заболеваний, диагностику и контроль среди уязвимых групп в приграничных районах и вдоль экономических коридоров, развитию изменений в цепочках создания стоимости, упрощению процедур торговли сельскохозяйственными продуктами и созданию коридоров по сохранению биоразнообразия и управлению водосборными бассейнами.

Перспективные задачи развития сотрудничества в рамках региона Стран Большого Меконга заключаются в том, чтобы выгоды от трансграничной торговли пропорционально распределялись по стране, трансформация сфер хозяйствования выходила за рамки простого обслуживания транзитной функции, а также нужна защита от негативных внешних эффектов повышения трансграничной мобильности людей и товаров.

Перспективное развитие Лаосской Народно-Демократической Республики предусматривает размещение точек роста-особых экономических зон на территориях с экономически выгодным доступом к рынкам, что способствует переносу производства рыночных товаров и услуг ближе к рынкам потребления, на приграничные территории с Королевством Таиланд, Вьетнамом и Камбоджей. Для устранения диспропорций сложившейся хозяйственно-экономической и пространственной системы Лаоса за счет экономически обоснованного размещения производительных сил и формирования условий их инновационного и инфраструктурного развития правительство страны создало специальные нормы законодательства в качестве основы для развития Особых экономических зон (ОЭЗ) и поощрения инвестиций. В настоящее время в Лаосской НДР насчитывается 13 ОЭЗ, семь из которых были созданы на основе режима концессий. Еще шесть ОЭЗ были недавно созданы в приграничных зонах с Королевством Таиланд, Вьетнамом, Камбоджей: Пхукхиао, Тха Кхэк, Бынг Тхат Луанг, Чампасак, Луангпрабанг и Донгпхоси. В рамках развития ОЭЗ особую значимость приобретает инвестиционное сотрудничество с Японией и Королевством Таиланд [8].

За прошедший пятилетний период развитие и управление ОЭЗ существенно продвинулись вперед, о чем свидетельствует увеличение инвестиций в эти проекты. Совокупная стоимость инвестиционных контрактов в этих зонах составляет 5 млрд 
В.А. Андреев, С. Ампхаван. Социально-экономическое развитие АНАР на современном этапе...

долл. США, а фактические инвестиции - 1,27 млрд долл. США, в том числе 16,3 млн долл. США из государственных инвестиций, 1005,2 млн долл. США инвестиций девелоперов и 250,5 млн долл. США от прочих инвесторов. В настоящее время в эти зоны вложено инвестиций от 249 компаний, в том числе 180 иностранных компаний, 48 отечественных компаний и 21 совместное предприятие.

Компании-резиденты ОЭЗ инвестировали в сектор услуг (49,37 процента), коммерческий сектор (34,6 процента) и промышленный сектор (16,03 процента). Это привело к созданию 15287 рабочих мест, из которых 6769 - занимают местные работники. Особые экономические зоны экспортировали товары на общую сумму 42855955 долл. США и импортировали товары на общую сумму 196465557 долл. США [8].

\section{Выводы}

В рамках исследования проведен анализ и выявлены особенности развития Лаосской Народно-Демократической Республики, рассмотрены стратегические перспективы ее развития до 2020 года.

В ходе исследования установлено, что Лаос провел значительные экономические и институциональные реформы, направленные на улучшение социального и экономического благосостояния населения, последовательно создавая рыночную экономику. Лаос достиг значительного экономического роста, провел приватизацию бывших государственных предприятий и добился макроэкономической стабильности. Кроме того, налицо значительное увеличение государственных и частных инвестиций и улучшение экономической деятельности как результат регионального и глобального экономического сотрудничества. Этим факторам способствовали ежегодные средние темпы роста экономики на 6-7 процентов в год с 1990 по 2016 год.

Анализ показал интерес к экономике страны иностранных инвесторов, поступает финансовая помощь от различных правительств и международных организаций. Вместе с тем рост экономики связан преимущественно с добычей природных ресурсов, где ограничено создание новых рабочих мест, остается низкая производительность в сельском хозяйстве, где большая часть рабочей силы продолжает заниматься низкоквалифицированным трудом.

Существуют проблемы для проведения реформы и привлечения инвестиций, как внутренних, так и иностранных. Поскольку страна сталкивается с недостатком профессиональных кадров, который сдерживает рост современного производственного сектора, более высокие инвестиции в образование и профессиональную подготовку должны соответствовать либерализации в бизнес-среде.

Однако Лаос обладает преимуществом географического местоположения для коммерческих грузовых перевозок и транзитных услуг в другие страны в рамках региона Большого Меконга. Кроме того, были усовершенствованы правовые инструменты, которые создадут благоприятную среду для содействия социальноэкономическому развитию. Членство в ВТО и АЕС расширит возможности для привлечения большего количества инвестиций, торговли и услуг в Лаосскую НДР, а также изучения опыта и уроков в области технологий и культуры, и создадут 
преимущества для дальнейшего социально-экономического развития страны в средне и долгосрочный период.

1. Информационный портал Азиатского банка развития. Информация о профиле Лаосской НДР [Электронный ресурc]. URL: https://www.adb.org/countries/lao-pdr/main

2. Сенгампхон П. Становление и развитие энергетического сектора Лаоса // Экономика и предпринимательство. 2013. № 12-3 (41-3). С. 154-159.

3. Damdouane Khouangvichit, Socio-Economic Transformation and Gender Relations in Lao PDR, UMEA University (2010), pp.15-29.

4. Economic Diversification, Structural Reforms Needed for Lao PDR to Achieve Inclusive Growth - Report [Электронный ресурc]. URL: http://www.adb.org/news/economic-diversification-structural-reforms-needed-lao-pdr-achieve-inclusive-growth-report

5. Hatthachan Phimphanthavong. Economic Reform and Regional Development of Laos, Vol. 3, No. 2 (2012).

6. IFAD, Enabling poor rural people to overcome poverty: Lao People's Democratic Republic Country strategic opportunities programme, (3th August 2011), pp. 6-10.

7. Lao Economic Monitor May 2016: Challenges in Promoting More Inclusive Growth and Shared Prosperity [Электронный pecypc] // Recent economic developments and outlook (p.13) . URL: http://www.worldbank.org/en/country/lao/publication

8. Lao economic monitor: towards restoring macroeconomic stability and building inclusive growth [Электронный ресурc]. URL: http://documents.worldbank.org/curated/ en/612411468047784529

9. Lowering Risks and Reviving Growth: Lao PDR Economic Update [Электронный ресурс]. URL: http://www.worldbank.org/en/news/press-release

10. Tetsuro Anan, The Current Situation and Outlook of the Lao Economy, No.17, pp. 1-16.

\section{Транслитерация}

1. Informatsionnyi portal Aziatskogo banka razvitiya. Informatsiya o profile Laosskoi NDR. URL: https://www.adb.org/countries/lao-pdr/main

2. Sengampkhon P. Stanovlenie i razvitie energeticheskogo sektora Laosa, Ekonomika $i$ predprinimatel'stvo, 2013, No 12-3 (41-3), pp. 154-159.

() В.А. Андреев, 2018

(c) Сайнявонг Ампхаван, 2018

Для цитирования: Андреев В.А., Сайнявонг Ампхаван. Социально-экономическое развитие Лаосской Народно-Демократической Республики на современном этапе: специфика, противоречия и перспективы // Территория новых возможностей. Вестник Владивостокского государственного университета экономики и сервиса. 2018. Т. 10. №3. С. 19-28.

For citation: Andreev V.A., Amphavanh Xayavong. Ongoing processes, contradictions and prospects of social and economic development in Lao PDR, The Territory of New Opportunities. The Herald of Vladivostok State University of Economics and Service, 2018, Vol. 10, No3, pp. 19-28.

DOI dx.doi.org/10.24866/VVSU/2073-3984/2018-3/019-028

Дата поступления: 19.07.2018. 